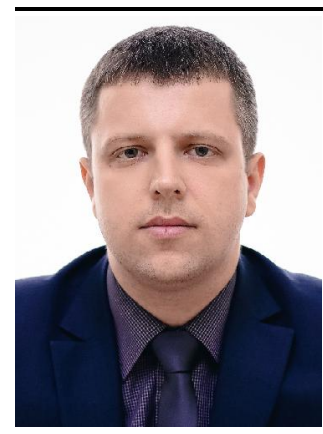

УДК $631.158: 658.3$

https://doi.org/10.47612/978-985-7149-55-1-2020-54-58

\author{
Андрей Грибов, кандидат экономических наук, доцент, \\ декан экономического факультета \\ Гродненский государственный аграрный университет, г. Гродно
}

\title{
Проблемные аспекты формирования кадрового потенциала сельскохозяйственных организаций
}

Сельскохозяйственное производство является базисом при обеспечении продовольственной безопасности страны, а также соблюдении принятых Республикой Беларусь обязательств по выполнению условий реализации Повестки дня в области устойчивого развития на период до 2030 года (ликвидация голода, улучшение питания и др.). Эффективность сельского хозяйства в значительной степени зависит от рационального использования всех видов ресурсов, однако для результативного применения необходимо их наличие. Это является крайне актуальным для формирования кадрового потенциала в условиях перехода к цифровой экономике.

В общем виде большинство авторов определяют кадровый потенциал предприятия как совокупные возможности кадров организации, которые необходимы для выполнения организационных целей и задач. Он включает и неиспользуемые возможности работников и лиц, которые имеют соответствующую квалификацию, но в настоящей момент не заняты по назначению или вообще не работают. Следовательно, кадровый потенциал рассматривают как фактический и как перспективный. Фактический кадровый потенциал адекватен составу кадров отрасли (организации), под которым подразумевается совокупность сотрудников, выполняющих определенные функции в процессе производственной деятельности на базе выявленных (известных) способностей. Перспективный кадровый потенцииал характеризует максимальные возможности кадров, которые можно достичь при улучшении условий хозяйствования и оптимальном использовании способностей работников [6].

Следует отметить, что кадровый потенциал как отдельной организации, так и отрасли (сферы) не является постоянной величиной. Его количественные и качественные характеристики постоянно меняются под воздействием целого комплекса факторов. Недостаточный кадровый потенциал системы препятствует ее развитию, максимальному использованию потенциала других ресурсов. В свою очередь, оптимальный кадровый потенциал, не нашедший своей реализации, использующийся неэффективно, ведет к существенному перерасходу ресурсов. В рамках реализации стратегии инновационного развития и повышения конкурентоспособности аграрного сектора особое значение приобретает проблема эффективного формирования кадрового потенциала отрасли. Создание надежной системы обеспечения кадрами и на этой основе обеспечение устойчивого функционирования сельскохозяйственных организаций являются приоритетной задачей.
Формирование кадрового потенциала сельскохозяйственных организаций базируется на демографических и социально-экономических процессах, сложившихся преимущественно в сельской местности. Численность сельского населения в 2010 г. составляла 2358,8 тыс. чел., а в 2019 г. на 245,4 тыс. чел. меньше (на 10,4 \% к 2010 г.), численность занятых в сельском хозяйстве (сельское, лесное и рыбное хозяйство) в 2010 г. составляла 494,5 тыс. чел., тогда как в 2019 г. (на конец года) - 332,6 тыс. чел., или снизилась на $32,7 \%$. Подобные тенденции обусловлены как снижением численности населения в сельской местности, так и рядом других факторов.

Структура и численность работников сельского хозяйства на конец 2019 г. представлены на рисунке 1.

В 2019 г. среди мужчин рабочие составляли $81,3 \%$, руководители - 7,8, специалисты - 10,5 и другие служащие $-0,4 \%$; среди женщин - 67,6; 9,$1 ; 22,2$ и 1,1\% соответственно.

Основным направлением обеспечения кадрового потенциала сельскохозяйственных организаций является постепенное увеличение численности молодежи и обновление трудовых ресурсов. Однако за 2014-2019 гг. складывалась противоположная ситуация, когда наибольший удельный вес в структуре кадров занимали люди зрелого и предпенсионного возраста. В 2014 г. удельный вес работников до 40 лет составлял порядка $40 \%$, а в 2019 г. - 36,2 \%, также существенно увеличивается количество работников старше 55 лет (табл. 1).

В условиях дефицита квалифицированных специалистов в отрасли, низкого престижа сельскохозяйственного труда многие руководители формируют штат из

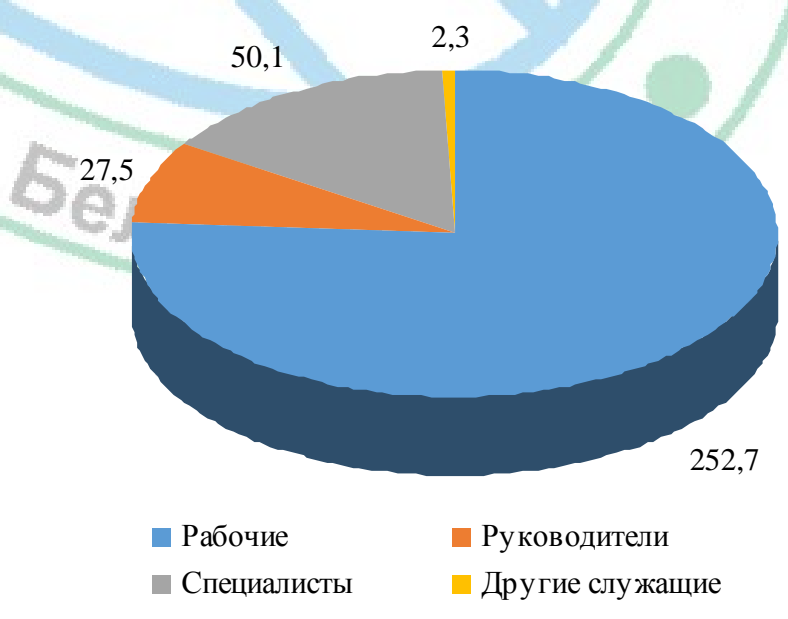

Рис. 1. Структура и численность работников сельского хозяйства, тыс. чел.

Примечание. Рисунки 1-3 составлены автором по данным [2, 3]. 
Таблица 1. Возрастная структура работников сельского хозяйства, чел.

\begin{tabular}{|c|c|c|c|c|c|c|}
\hline \multirow{2}{*}{ Год } & \multicolumn{7}{|c|}{ Возраст, лет } \\
\cline { 2 - 7 } & до 25 & $25-29$ & $30-39$ & $40-49$ & $50-54$ & 55 и старше \\
\hline 2014 & 28991 & 37691 & 89422 & 110068 & 65793 & 62959 \\
\hline 2019 & 18865 & 26926 & 74484 & 89121 & 52686 & 70519 \\
\hline
\end{tabular}

Примечание. Таблицы 1-3 составлены автором по данным [2, 3].

имеющегося кадрового потенциала часто с недостаточным образовательным уровнем и несоответствующей специальностью.

Современный уровень развития белорусского агропромышленного комплекса требует специальных навыков и умений, сформированных у специалистов в процессе обучения в учебных заведениях. Положительным моментом является увеличение в относительном соотношении численности работников с высшим и средним специальным образованием. Однако удельный вес работников с высшим образованием в 2014 г. составлял $10,3 \%$, а в 2019 г. - 12,7\%, что является недостаточным для функционирования отрасли и становления цифровой экономики. Образовательная структура и численность работников аграрной отрасли представлены на рисунке 2 .

В данном аспекте ключевым моментом является создание единой системы кадрового обеспечения сельского хозяйства, включающей профессиональную ориентацию потенциальных абитуриентов, подготовку специалистов среднего специального и высшего образования, а также переподготовку и повышение квалификации кадров до уровня, позволяющего наиболее эффективно использовать кадровый потенциал.

В 2019 г. был осуществлен выпуск специалистов со средним специальным образованием и квалифицированных рабочих с профессионально-техническим образованием в количестве 7,2 тыс. чел., что ниже уровня 2010 г. на 3,5 тыс. чел. Выпуск специалистов с высшим образованием составил в 2019 г. 5,3 тыс. чел., что выше уровня 2010 г. на 15,2 \% (табл. 2). Это является следствием имеющихся свободных вакансий в сельском хозяйстве из-за высокого уровня текучести кадров, в первую очередь руководителей и специалистов.

Анализ трудовых ресурсов сельского хозяйства показывает, что количественные и качественные характеристики кадрового потенциала не соответствуют потребностям отрасли и не позволяют полномасштабно использовать достижения НТП. Количество работников неуклонно снижается, наряду с недостаточным уровнем образования. Решение существующих проблемных аспектов должно носить комплексный характер и учитывать важность материального компонента в побуждении к действенному и высокопроизводительному труду. Следует помнить, что АПК функционирует в условиях повышенных рисков, обусловленных зачастую не зависящими от человека природно-климатическими факторами.

Таким образом, комплексный всесторонний анализ позволил выявить основные причины отсутствия мощного кадрового потенциала в аграрном секторе.

1. Низкий уровень заработной плать. Для закрепления трудовых ресурсов в сельской местности необходимо совершенствование материальных стимулов для высокопроизводительного труда. Определяющим показателем, влияющим на выбор места трудоустройства для наемных работников, является заработная плата. Уровень заработной платы в сельском хозяйстве не подымался выше $74 \%$ от уровня средней по республике за 2010-2019 гг. (рис. 3).

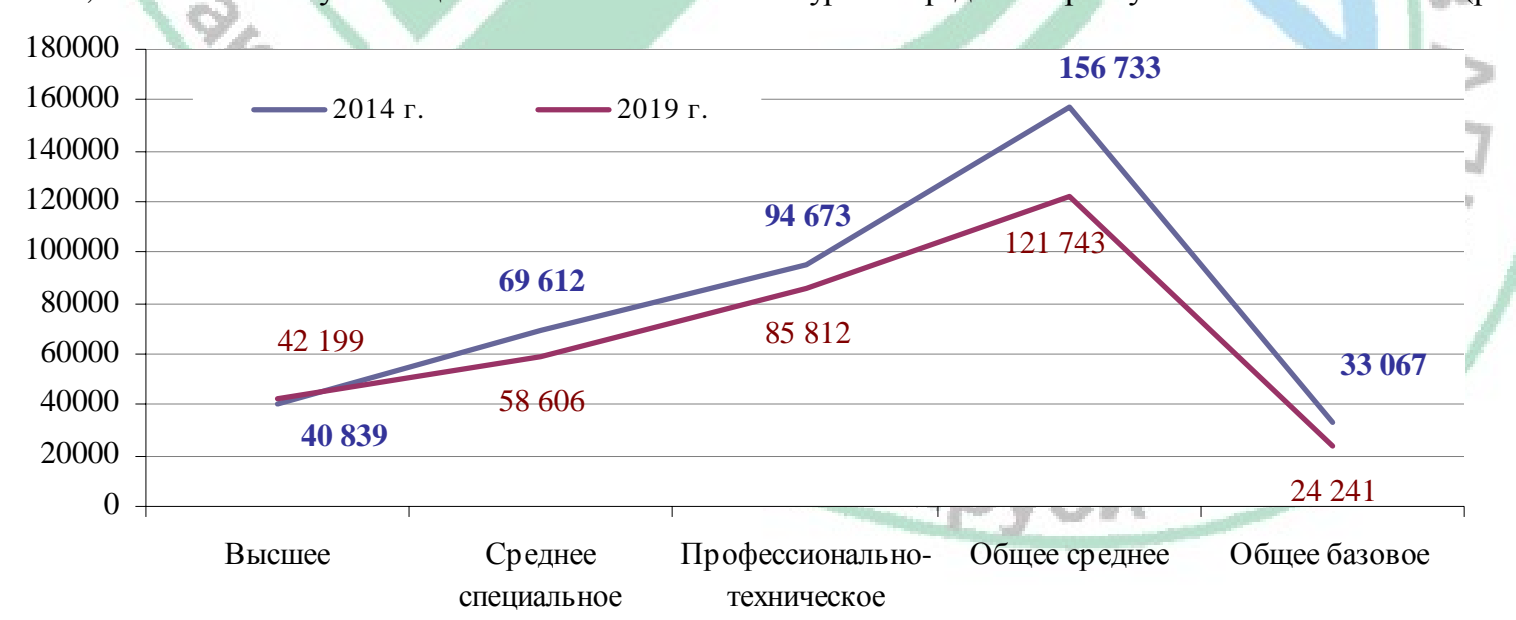

Рис. 2. Образовательная структура работников сельского хозяйства, чел.

Таблица 2. Выпуск специалистов по профилю «Сельское и лесное хозяйство. Садово-парковое строительство», тыс. чел.

\begin{tabular}{|l|c|c|c|c|c|c|}
\hline \multicolumn{1}{|c|}{ Специлисты } & \multicolumn{3}{c|}{ Год } & \multirow{2}{*}{$\begin{array}{c}2019 \text { г. к } \\
2010 \text { г., \% }\end{array}$} \\
\cline { 2 - 8 }$n$ & 2010 & 2015 & 2017 & 2018 & 2019 & 115,2 \\
\hline С высшим образованием & 4,6 & 5,2 & 5,0 & 4,8 & 5,3 & 62,1 \\
\hline Со средним специальным образованием & 6,6 & 5,1 & 4,4 & 4,1 & 4,1 & 6 \\
\hline $\begin{array}{l}\text { Квалифицированные рабочие с профессионально- } \\
\text { техническим образованием }\end{array}$ & 4,1 & 3,1 & 3,2 & 3,1 & 3,1 & 75,6 \\
\hline
\end{tabular}




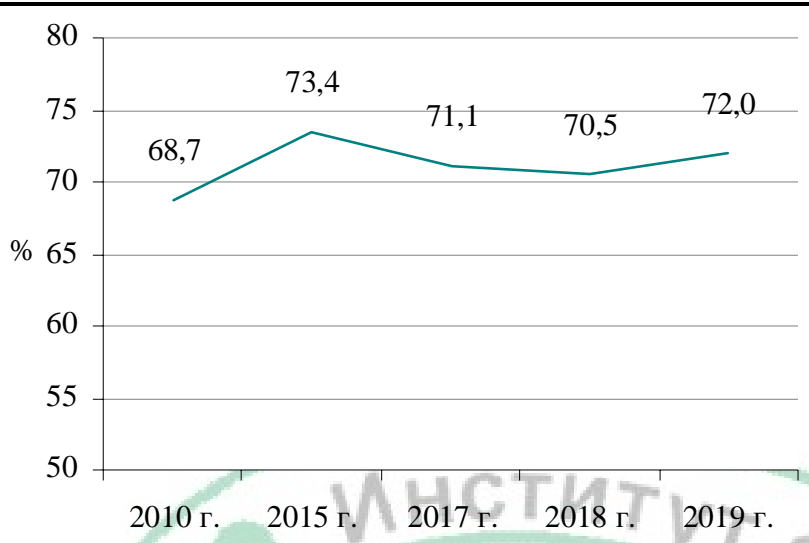

Рис. 3. Средний уровень номинальной начисленной заработной платы в сельском хозяйстве по отношению к среднереспубликанскому, \%

За анализируемый период увеличение номинальной начисленной заработной платы в сельском хозяйстве по отношению к среднереспубликанскому значению составило всего 3,3 \%, что негативно сказывается на привлечении и закреплении специалистов в данной отрасли.

В странах с рыночной экономикой решение проблемы взаимосвязи экономических интересов собственников и наемных работников, повышение эффективности производства в капиталистическом обществе осуществляются в основном посредством вовлечения работников в процесс воспроизводства не только в качестве рабочей силы, но и как собственника средств производства [5].

В соответствии с действующими в Республике Беларусь законодательными актами на предприятии часть чистой прибыли может быть передана в собственность членов трудового коллектива (долевая собственность). Формирование из части чистой прибыли долевой собственности в работе сельскохозяйственных организаций практически не применяется. В то же время очевидно, что формирование долевой рабочей собственности из прибыли, увеличивающей капитал предприятия, - это одно из проявлений капитализированной стоимости и способ стимулирования повышения эффективности производства.

Механизм участия в прибыли предприятия членов трудового коллектива по-прежнему недостаточно разработан. Во-первых, не изложен процесс капитализации этой части прибыли; во-вторых, не рассмотрен порядок персонификации части прибыли, передаваемой в собственность трудового коллектива; в-третьих, вызывает сомнение правомерность источника и размера определения части прибыли, направляемой на выплату процентов. Распределение части прибыли, передаваемой в собственность трудового коллектива, непосредственно отдельным членам было бы правомерно производить с учетом их влияния на конечный результат производства [5].

2. Мигращия населения. Миграция является одной из важнейших проблем народонаселения и рассматривается не только как простое механическое передвижение людей, а как сложный общественный процесс, затрагивающий многие стороны политической и социально-экономической жизни [1].

Внешняя миграция рассматривается как один из основных источников формирования человеческого капитала страны. Трудовые миграционные процессы, в основе которых, как правило, лежат экономические причины, занимают особое место в демографическом и социально-экономическом развитии любой страны. Начало социально-политических и экономических трансформаций в Беларуси послужило импульсом к усилению внутренней миграции населения в Республике Беларусь [8].

Количество мигрирующего населения внутри республики изменяется ежегодно и не имеет постоянной тенденции как между областями, так и внутри районов (табл. 3).

В сельских населенных пунктах за 2010-2019 гг. количество выбывающего населения превышает количество прибывающего, что объясняется как старением сельского населения с вытекающими процессами, так и миграцией трудовых ресурсов из села в город, где население имеет более высокий уровень доходов.

Сложившаяся тенденция прослеживается и во внешней миграции, подтверждением данного тезиса служит выход на четвертое место среди наиболее популярных для эмиграции направлений динамично развивающейся Республики Польша, где процесс трудоустройства, поступления в учебные заведения, получения вида на жительство для граждан Республики Беларусь является одним из наиболее простых среди всех развитых стран. Это стало причиной того, что с 2014 г. количество ежегодно выезжающих в Польшу белорусов увеличилось более чем в 3,3 раза. Несмотря на происходящие изменения, Российская Федерация остается основной страной, принимающей белорусских трудовых мигрантов. К факторам, привлекающим белорусов, можно отнести: устойчивый спрос на работников ввиду демографического кризиса, происходящего в России; более высокий уровень заработной платы; отсутствие визового режима; низкие транспортные издержки; общность культуры и языка [8].

Актуальной для сельского хозяйства является разработка ряда конкретных мероприятий, которые позволят

Таблица 3. Миграционные процессы в сельских населенных пунктах, тыс. чел.

\begin{tabular}{|l|c|c|c|c|c|}
\hline \multirow{2}{*}{\multicolumn{1}{|c|}{ Миграция }} & \multicolumn{5}{c|}{ Год } \\
\cline { 2 - 6 } & 2010 & 2015 & 2017 & 2018 & 2019 \\
\hline Внутриреспубликанская & -35798 & -14765 & -3333 & -10351 & -9913 \\
\hline Межобластная & -7245 & 1650 & 4609 & 2146 & 4160 \\
\hline Внутриобластная & -28553 & -16415 & -7942 & -12497 & -14073 \\
\hline Межрайонная & -17974 & -7195 & -2760 & -5354 & -5776 \\
\hline Внутрирайонная & -10579 & -9220 & -5182 & -7143 & -8297 \\
\hline
\end{tabular}


получить положительный экономический эффект от умеренной трудовой миграции и сохранения высококвалифицированных специалистов в отрасли.

3. Условия трудовой деятельности. Труд в сельском хозяйстве республики имеет значительные отличия от труда в других сферах деятельности. Нами выделены основные особенности управленческого (руководители и главные специалисты) труда в сельском хозяйстве:

- строгое выполнение прогнозных показателей по производству и реализации продукции, лишение возможности самостоятельного выбора специализации предприятия;

- отсутствие прозрачности распределения государственных дотаций и субсидий, равноправной доступности к льготному кредитованию;

- чрезмерная регламентация закупочно-снабженческой деятельности;

- управление производством в условиях низкой квалификации работников и дефицита рабочей силы;

- ведение хозяйственной деятельности под постоянным наблюдением контрольно-ревизионных служб и инспекций;

01 несоблюдение интересов собственников имущества;

- отсутствие свободной возможности материальных и нематериальных форм поощрения работников;

- личная ответственность за производственно-хозяйственную деятельность всего предприятия;

- наличие ненормированного рабочего дня;

- неудовлетворенность работников условиями труда и быта, социальной и производственной инфраструктурой, морально-психологическим климатом, территориальным местоположением организаций;

- ограниченные возможности для проявления профессиональной инициативы и самостоятельности;

- наличие синдрома эмоционального выгорания ввиду высокой стрессовой нагрузки и напряженности труда.

В сельскохозяйственных организациях необходимо индивидуально для каждого работника разработать систему материальных и нематериальных форм поощрения, создать благоприятный социально-психологический климат, снизить напряженность труда.

Вышеперечисленные признаки труда в сельском хозяйстве приводят к высокому уровню текучести кадров. В отдельных сельскохозяйственных организациях за год сменяется по несколько специалистов и руководителей, что отрицательно сказывается на экономической эффективности производства. Для закрепления и удержания кадров в сельской местности необходимо разработать комплекс мер, направленных на совершенствование материальных и моральных стимулов для высокопроизводительного труда.

Отдельными отечественными учеными $[4,7]$ для повышения эффективности использования потенциала руководящих работников и специалистов аграрной отрасли предлагается реализация следующих мер:

- предоставить руководителям и специалистам большую самостоятельность в принятии управленческих решений в плане развития сельскохозяйственных организаций;

- провести структурные преобразования сельскохозяйственных предприятий с усилением роли института частной собственности;

- создать систему мониторинга для определения текущей и перспективной потребности в компетентных квалифицированных кадрах АПК в разрезе профилей и специальностей;

- создать региональные центры оценки и сертификации персонала для отбора контингента слушателей, кандидатов на обучение по предлагаемой программе, а также специалистов в резерв на должности руководителей, содействовать укреплению этих структур соответствующими кадрами, организации их обучения и стажировки, обеспечению необходимыми методиками отбора и техническими средствами;

- укрепить уровень квалификации профессорско-преподавательского состава учреждений, обеспечить их непрерывное обучение в организациях АПК, в том числе в зарубежных странах, внедряющих инновационные технологии и достигших высоких производственно-экономических результатов; привести структуру подготовки педагогических кадров в соответствие их потребности;

- широко внедрить в практику проектного обучения специалистов профессиональную подготовку и повышение квалификации работников АПК, предполагающую формирование проектных команд, направленных на решение конкретных производственных задач.

Анализ обеспечения сельскохозяйственных предприятий трудовыми ресурсами позволяет резюмировать, что наличие кадрового потенциала не соответствует требованиям построения инновационной и цифровой модели аграрной отрасли. Синергетический эффект от выделенных основных причин сложившейся ситуации приводит к состоянию, когда уровень использования основного ресурса повышения эффективности остается достаточно низким и существует необходимость разработки действенного механизма формирования кадрового потенциала в сельском хозяйстве.

\section{Список использованных источников}

1. Артюхин, М. И. Основные проблемы миграции населения Республики Беларусь: социологический анализ [Электронный ресурс] / М. И. Артюхин, С. А. Пушкевич. - Режим доступа: https://cyberleninka.ru/article/ n/osnovnye-problemy-migratsii-naseleniya-respublikibelarus-sotsiologicheskiy-analiz. - Дата доступа: 17.09.2020.

2. Статистический ежегодник : стат. сб. / редкол.: И. В. Медведева [и др.] ; Нац. стат. ком. Респ. Беларусь. Минск, 2020. - 436 с.

3. Труд и занятость в Республике Беларусь : стат. сб. / редкол.: И. В. Медведева [и др.] ; Нац. стат. ком. Респ. Беларусь. - Минск, 2020. - 314 с.

4. Человеческий капитал как определяющий фактор инновационного развития аграрной экономики /А. В. Турьянский [и др.] // Актуальные проблемы 
формирования кадрового потенциала для инновационного развития АПК : сб. ст. IV Междунар. науч.-практ. конф., Минск, 5-6 окт. 2017 г. - Минск : БГАТУ, 2018. C. 25-34.

5. Экономика организаций и отраслей агропромышленного комплекса : в 2 кн. / В. Г. Гусаков [и др.] ; под общ. ред. В. Г. Гусакова. -Минск : Белорус. наука, 2007. $891 \mathrm{c.}$

6. Юшина, Л. Н. Совершенствование кадрового обеспечения регионального АПК на основе инновационного развития системы профессиональной подготовки : дис. ... канд. экон. наук : 08.00.05 / Л. Н. Юшина. Воронеж, 2004.-166 c.
7. Яковчик, Н. С. Формирование кадрового потенциала для инновационного развития агропромышленного комплекса Союзного государства / Н. С. Яковчик, И. Н. Шило, Н. Н. Романюк // Научное сопровождение инновационного развития агропромышленного комплекса: теория, практика, перспективы: в 2 ч. : материалы 65 Междунар. науч.-практ. конф., Рязань, 20-21 мая 2014 г. / ФГБОУ ВПО «Рязанский ГАУ им. П. А. Костычева». - Рязань, 2014. - Ч. 2. - С. 384-385.

8. Hrybau, A. Features and trends in external migration in the Republic of Belarus / A. Hrybau, V. Kulakou, A. Napiorkowska-Baryla // Olsztyn Economic Journal. 2020. - №1 (15). - P. 63-77.

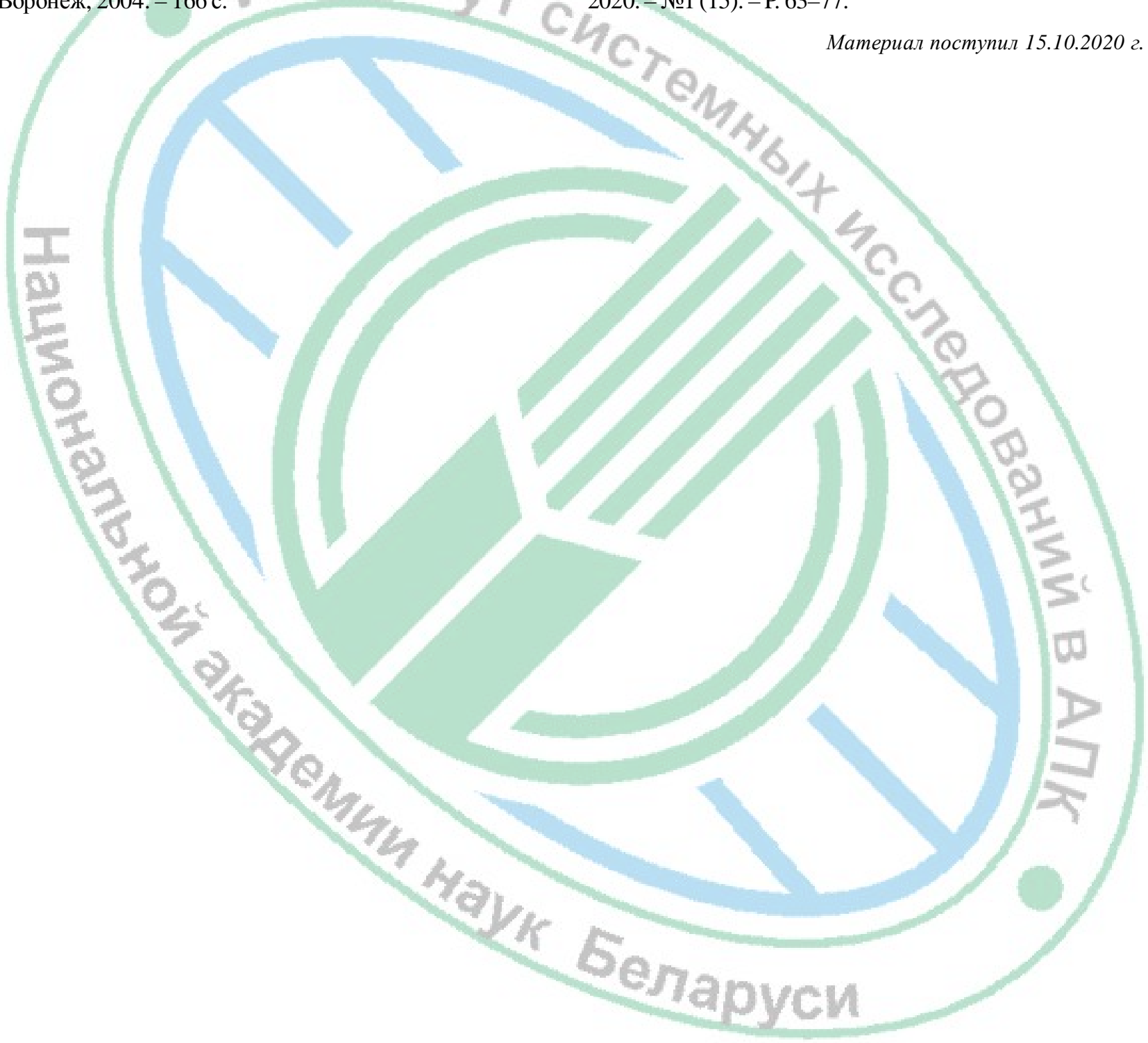

